\title{
EXPERIMENTAL SET UP VERIFICATION OF SERVO DC MOTOR POSITION CONTROL BASED ON INTEGRAL SLIDING MODE APPROACH
}

\author{
Ali Mohamed Yousef Ali \\ Electrical Engineering Department, Faculty of Engineering, \\ Assiut University, Egypt, drali_yousef@yahoo.com
}

(Received June 20, 2011 Accepted August 4, 2011)

In this paper, a novel controller based on the Integral Sliding Mode Controller (ISMC) is proposed and designed for controlling DC motor in a servo drive. The modeling and analysis of the servo DC motor are obtained. To improve the controller performance in steady state (zero error), the integral sliding mode controller (ISMC) is designed and evaluated. Since the main drawback of SMC is a phenomenon, that called chattering resulting from discontinuous controllers. An ISMC with switched gains is used for chattering reduction and controller robustness. For comparison, the proposed ISMC with switched gains is compared with that of a PID controller. Experimental verification and simulations have been carried out in order to validate the effectiveness of the proposed scheme. The proposed controller offers very good tracking, also it is highly robust and controlled plant reached very fast to the final position. Furthermore the application of the SM ensures reduction of the system order by one and quick recovery from matched disturbance in addition to good tracking. Moreover, this scheme is robust against the parameters variations.

KEYWORDS: Servo DC motor, integral sliding mode control, PID controller.

\section{INTRODUCTION}

Recently, DC servo motors have been widely used as an actuator for motion control and direct-drive applications. Examples are as robotic and actuator for automation process, mechanical motion and others. This is because the well controllability features of the DC servo motors and they have adaptability to various types of control methods. The DC servo motors have been extensively applying in many servomechanisms. Therefore, it is very important to study about the position control of the DC servo motors. Generally, the DC servo motor systems have uncertain and nonlinear characteristics which degrade performance of controllers. Based on these reasons, Sliding Mode Control (SMC) is one of the popular control strategies and powerful control technology to deal with the nonlinear uncertain system [1]

AC and DC servomotors [2,3] are in use in many applications. Particularly, DC ones are used in computer peripherals and robot manipulators and are characterized by: ability to produce full continuous torque, controlled braking is relatively simple and low cost as compared with similar AC drives at high powers. Sliding mode control theory was introduced for the first time in the context of the variable structure systems 
(VSS). It has become so popular that now it represents this class of control systems. Even though, in its early stages of development, the SMC theory was overlooked because of the development in the famous linear control theory. Recently, the variable structure control strategy using the sliding-mode has been focused on many studies and research for the control of the DC servo drive systems [4-8]. The sliding-mode control can offer many good properties, such as good performance against unmodeled dynamics, insensitivity to parameter variations, external disturbance rejection and fast dynamic response [9]. These advantages of the sliding-mode control may be employed in the position and speed control of a DC servo system.

The design of SMC consists of two main steps. Firstly; one can select a sliding surface that models the desired closed loop performance. Secondly, a control law is designed such that the system state trajectory is forced toward the sliding surface. The system state trajectory in the period of time before reaching the sliding surface is called the reaching phase. The system dynamics in the reaching phase is still influenced by uncertainties. Ideally, the switching of the control should occur at infinitely high frequency to eliminate the deviation from sliding manifold. In practice, the switching frequency is not infinitely high due to the finite switching time. Thus, undesirable chattering appears in the control effort. Chattering is highly undesirable because it excites un-modeled high frequency plant dynamics and this can cause unforeseen instability [9]. Different studies tried to solve this problem by combining fuzzy or neural controller with the sliding mode $[10,11]$.

In this paper, the position control of the DC motor in servo drive has been developed based on SM approach. A novel scheme using Integral sliding mode (ISM) controller with switched gains has been investigated. The system responses are compared when PID controller is applied to the system. A PID controller is selected because the cost of implementation is inexpensive and is widely used in industry. SMC methods yield nonlinear controllers which are robust against un-modeled dynamics and, internal and external perturbations. An experiments and computer simulations are performed to show the validity of the proposed system. The results obtained with ISMC with changed gains are compared with the traditional SMC and PID controller. The advantages and limitations of each method are discussed.

In this study, the integral control based on sliding surface has been adopted to control the motion of a DC servo motor to achieve the desired position tracking performance. The goal of this study of the servo motor system is to achieve robustness against system parameter variations and any external disturbances. This study will present the system description and the proposed control technique design. Stability analysis of the proposed integral control technique was derived in stability analysis [1]. The comparisons of the proposed ISMC technique with a conventional PID and SMC controllers that demonstrated faster response, more robustness to parameter variations and external disturbances than the other controllers that will be presented in results., then conclusion will be given.

\section{PLANT DESCRIPTIN}

The plant consists of a DC motor with an inertial load. The DC motor is separately excited and armature controlled, whose schematic diagram is shown in Fig.1. In this section design of controller to control the motor-load angle speed is proposed. The 
system parameters are shown in appendix. A block diagram of the DC servomotor with automatic voltage regulator (AVR) is shown in Fig.2.

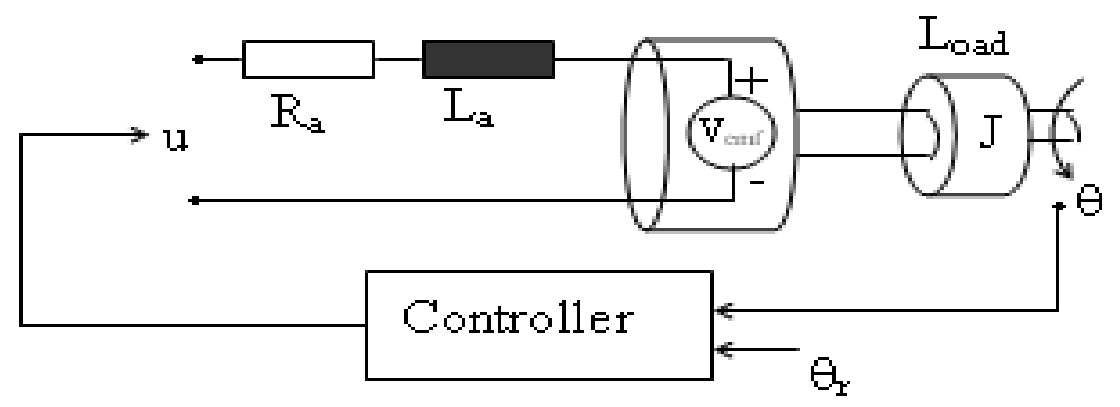

Fig.1: DC Servomotor circuit diagram

The state equations that describe the DC servomotor behavior [2,12] are:

$$
\begin{gathered}
\frac{d^{2} \theta}{d t^{2}}=\frac{K_{m}}{J} i_{a}-\frac{K_{f}}{J} \frac{d \theta}{d t}-T_{L} \\
\frac{d i_{a}}{d t}=-\frac{R_{a}}{L_{a}} i_{a}-\frac{K_{b}}{L_{a}} \frac{d \theta}{d t}+\frac{V_{a}}{L_{a}}
\end{gathered}
$$

Let

$V_{a}=u$

Substituting (1) into (2) and using (3) one gets:

$$
u \frac{K_{m}}{R_{a} J_{m}}=\frac{d^{2} \theta}{d t^{2}}+\left[\frac{B R_{a}+K_{m}^{2}}{R_{a} J_{m}}\right] \frac{d \theta}{d t}+\left[\frac{1}{J_{m}}\right] T_{L}
$$

In state space matrix form, one gets:

$$
\frac{d x}{d t}=A x+B u+D v
$$

Where

$$
A=\left[\begin{array}{cc}
0 & 1 \\
0 & -\frac{B R_{a}+K_{m}^{2}}{R_{a} J_{m}}
\end{array}\right], \quad B=\left[\begin{array}{c}
0 \\
\frac{K_{m}}{R_{a} J_{m}}
\end{array}\right], \quad D=\left[\begin{array}{c}
0 \\
-\frac{1}{J_{m}}
\end{array}\right]
$$

with $x=\left[\begin{array}{ll}x_{1} & x_{2}\end{array}\right]^{t}, x_{1}=\theta, x_{2}=\frac{d \theta}{d t}=\omega, v=T_{L}$

and

$x_{1} \quad$ rotor position

$x_{2} \quad$ rotor speed

$u \quad$ control input 


\section{$v \quad$ disturbance \\ $\mathrm{t}$ transpose}

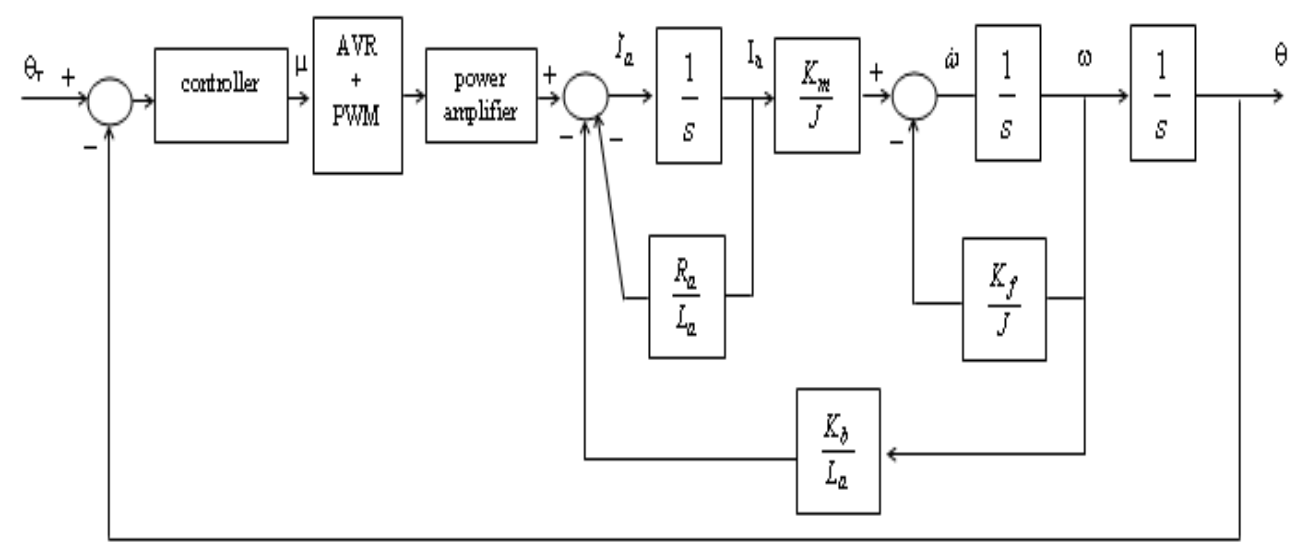

Fig. 2: Block diagram of the DC motor with AVR.

\section{INTEGRAL SLIDING MODE CONTROLLER}

In this section, first the design of the SM controller is described and later, based on the analysis and interpretation of the controller block diagram we introduce the proposed ISM controller is introduced.

The sliding surface $\sigma$ is defined as:

$$
\sigma=\dot{e}+C \cdot e=\left(\theta_{r}-\theta\right) \cdot C+\dot{\theta}_{r}-\omega
$$

where

$\theta_{r} \quad$ the position reference

C a positive constant

From the second theorem of Lyapunov, the stability condition can be written as:

$$
\frac{1}{2} \cdot \frac{d \sigma^{2}}{d t}=\sigma \cdot \dot{\sigma} \leq-K|\sigma|
$$

Where: $\frac{1}{2} \cdot \sigma^{2}>0$ (positive definite) is a Lyapunov function and $\mathrm{K}$ a positive constant. The control voltage command is calculated by substituting $\sigma$ and $\dot{\sigma}$ in equation (8) as follows [2,13]:

$$
u=\frac{R_{a} J_{m}}{K_{m}}\left[\ddot{\theta}_{r}+C \cdot \dot{\theta}_{r}+\left(\frac{B R_{a}+K_{m}^{2}}{R_{a} J_{m}}-C\right) \dot{\theta}+\frac{1}{J_{m}} T_{L}+K \cdot \operatorname{sign}(\sigma)\right]
$$

A block diagram of this conventional SM controller is shown in Fig.3. 
$\mathrm{T}_{\mathrm{L}}$

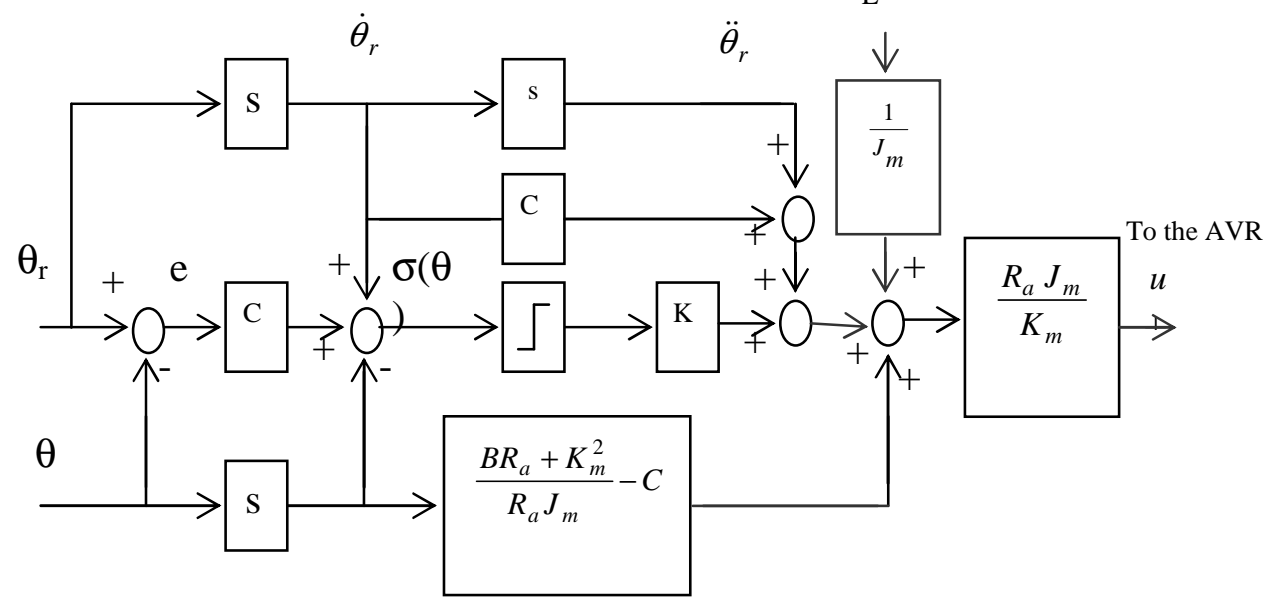

Fig. 3: Block diagram of the conventional SM controller

The problem with this conventional controller is that it has large chattering in the control output and the drive is very noisy. Furthermore, because of chattering, it is difficult to achieve small enough positioning error in steady state [13]. To reduce chattering the sign function (infinite gain) of the conventional SM is substituted with a finite gain $\mathrm{K}$ within a small boundary. This affects controller's robustness too, but still the controller will remain robust enough if gain $\mathrm{K}$ is chosen large enough. An infinite or very large gain $\mathrm{K}$ increases chattering because the bandwidth of the automatic voltage regulator (AVR) is not infinite. We assumed an ideal AVR and did not include it in the plant model, but this assumption holds as long as the bandwidth of the outer control loops does not exceed that of AVR. The selection of a finite $\mathrm{K}$ gain affects the sliding surface. By choosing a finite, appropriate value for $\mathrm{K}$ the chattering is greatly reduced [13]. The constant $\mathrm{C}$ basically determines the speed of response. It is the only parameter, which determines the dynamic of the system in SM. The choice of the constant $\mathrm{C}$ is also bounded from the AVR bandwidth and the encoder noise. Large values of constant $\mathrm{C}$ tend to faster response, but if the bandwidth of the AVR is exceeded this will lead in chattering and it will deteriorate the controller performance.

To reduce greatly the steady state error an integral block is added, which forces the system in steady state toward a zero error positioning. This integral block tends to slow down the transient response of the control system. For this reason it is switched on only when the system approaches the final position. On one hand the sliding mode tracks the reference very fast ensuring a very small tracking error till the final positioning is reached and on the other hand the integral block, taking advantage of the small initial error, reduces it to zero very fast. The gain $\mathrm{K}$ is switched to a larger value $\mathrm{K} 1$ right before the position command reaches the desired final value. The condition of switching is detected when speed and acceleration signals of the position command have opposite signs. This gain is returned to its previous value immediately after the final position is reached. This ensures a fast and precise stop of the servo. If a large gain will be applied all the time, chattering in the torque command will be inevitable. So, we have designed a controller, which has a very good tracking and reaches very fast the final position. The controller is also very robust to the outside disturbances or 
parameter uncertainties. A block diagram of the ISMC with switched gains is shown in Fig. 4.

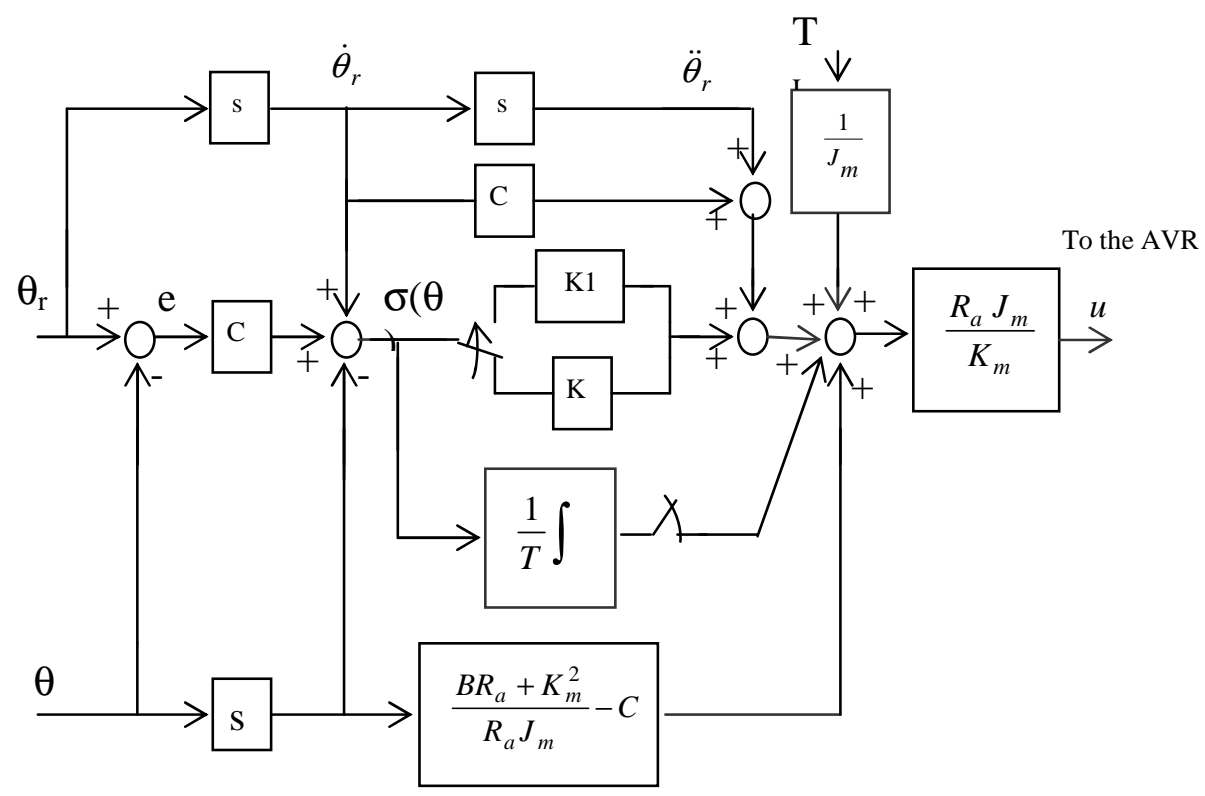

Fig. 4: Block diagram of the proposed ISM controller with switched gains

A Sliding Mode Controller is a Variable Structure Controller (VSC). Basically, a VSC includes several different continuous functions that can map plant state to a control. Surface and the switching among different functions are determined by plant state that is represented by a switching function. Without lost of generality, consider the design of a sliding mode controller for the following second order system[18] The position error is introduced:

$$
e(k)=\theta_{r e f}(k)-\theta(k)
$$

\section{Where;}

$\theta_{\text {ref }}(k), \theta(k)$ are the respective responses of the desired reference track and actual rotor position, at the $\mathrm{K}$ the sampling interval and $\mathrm{e}(\mathrm{k})$ is the position error. The sliding surface (s) is defined with the tracking error (e) and its integral ( $\left.\int e d t\right) \square$ and rate of change ( e )

$$
S=e+\lambda_{1} e+\lambda_{2} \int e d t
$$

Where

$\lambda_{1}, \lambda_{2}>0$ are a strictly positive real constant. The basic control law of Sliding Mode Controller

Where $\mathrm{K}$ is a is given by: $U=-k \operatorname{sgn}(s)$ constant parameter, sign $(\cdot)$ is the sign function and $\mathrm{S}$ is the switching function. 


\section{PID CONTROLLER}

PID controllers are dominant and popular and, have been widely used because one can obtain the desired system responses and it can control a wide class of systems. This may lead to the thought that the PID controllers give solutions to all requirements, but unfortunately, this is not always true [14]. Alternative tuning methods have been recently presented including disturbance reduction, magnitude optimum $[15,16]$, pole placement and optimization methods [16,17].

In this work, the PID optimal tuning method used is found in [17]. Where, the parameters of PID controller satisfying the constraints correspond to a given domain in a plane. The design plot enables identification of the PID controller for desired robust conditions, and in particular, gives the PID controller for lowest sensitivity. By applying this method, trade-off among high frequency sensor noise, low frequency sensitivity, gain and phase margin constraints are also directly available.

The transfer function of a PID controller is given by:

$$
K(s)=K_{p}\left(1+\frac{1}{T_{I} s}+T_{D} s\right)
$$

where $K_{p}, \frac{K_{P}}{T_{I}}$ and $K_{P} T_{D}$ represent the proportional, integral and derivative gains of the controller respectively. Define $\omega_{n}=\frac{1}{\sqrt{T_{I} T_{D}}}$ and $\zeta=\frac{1}{2} \sqrt{\frac{T_{I}}{T_{D}}}$ as the controller's natural frequency and the damping coefficient, respectively. Then the PID transfer function can be written as:

$$
K(s)=K_{P} \frac{\omega_{n}^{2}+2 \zeta \omega_{n} s+s^{2}}{2 \zeta \omega_{n} s}
$$

\section{RESULTS AND DISCUSSION}

The purpose of this part showing the powerful and robustness of the proposed SMC approaches as applied to a DC servo system. SMC and ISMC schemes are applied to control the position of the DC servomotor. Also, digital simulation and experimental setup verification are utilized to evaluate the model. The parameters of the DC motor are shown in table 2 in the appendix.

\subsection{Digital Simulation Results}

Figure 5 shows the position and speed time responses due to step change in the desired position angle $\left(\theta_{\mathrm{r}}\right)$ using SMC and PID controllers. It is seen that, applying a PID controller which its parameters has been tuned using the optimization method to the system when, there is no disturbance, the output completely tracks the desired position, but with the traditional SMC, the position achieved is slightly lower than the desired value. However, the settling time for SMC is less $(0.12 \mathrm{sec}$.) than the PID $(0.47 \mathrm{sec}$.$) .$ To remove this obstacle the ISMC is applied to the system. Fig. 6 shows the position and speed time responses using a PID controller and the classical SMC with matched disturbance, which shown in figure (6a). SMC is insensitive against the (matched) 
disturbance and the desired position is obtained even in the presence of disturbance. A well-tuned PID controller may reduce the effect of the disturbance on the system. However, by applying PID controller, it is impossible to reject the oscillations completely. The simulation results for ISMC when there is a random disturbance in the system is shown in Fig.7. The result shows the exact position is obtained (without steady state error) when ISMC is applied, and the disturbance doesn't affect the position. But when a PID controller is applied, the position and speed of the servo drive does not reach to steady state but make oscillation around the desired position. Appropriate PID can reduce this oscillation but it is impossible to reject the disturbance effect completely. Fig. 8 depicts the time response of the proposed ISMC and PID driven DC servo motor with disturbance and parameters changes. It should be seen that the system is robustly stable in spite of parameters variations. Moreover, the settling time and the overshoots calculation for position angle and rotor speed is depicted in Table 1.

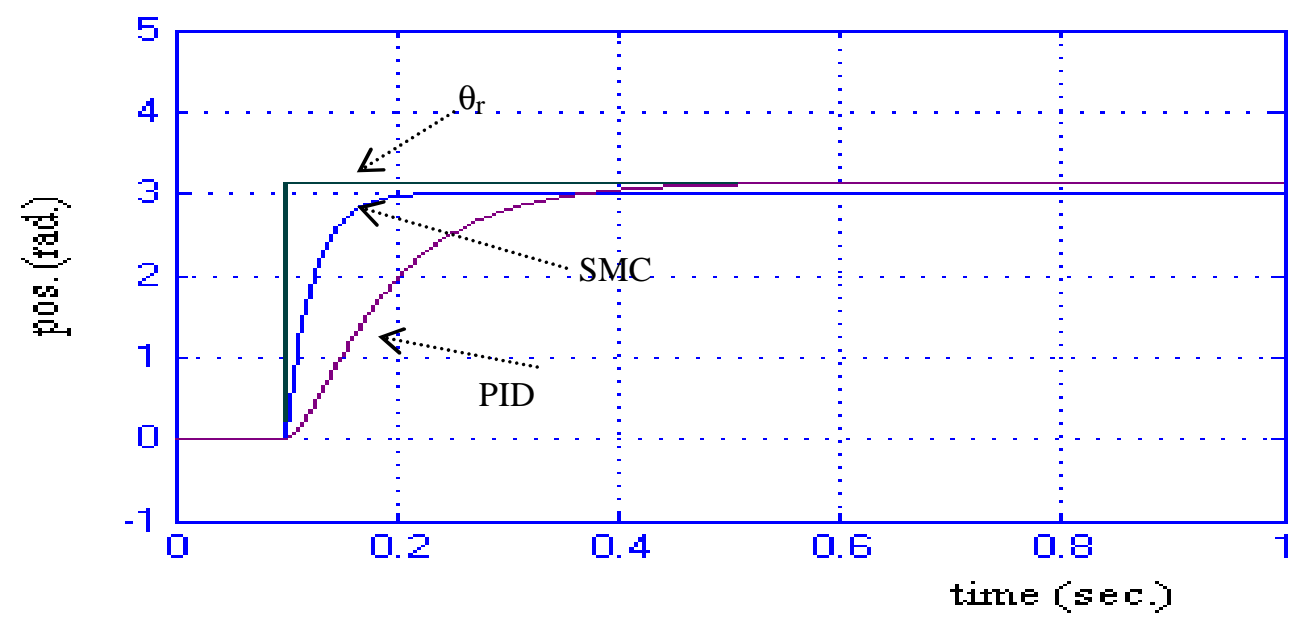

(a)

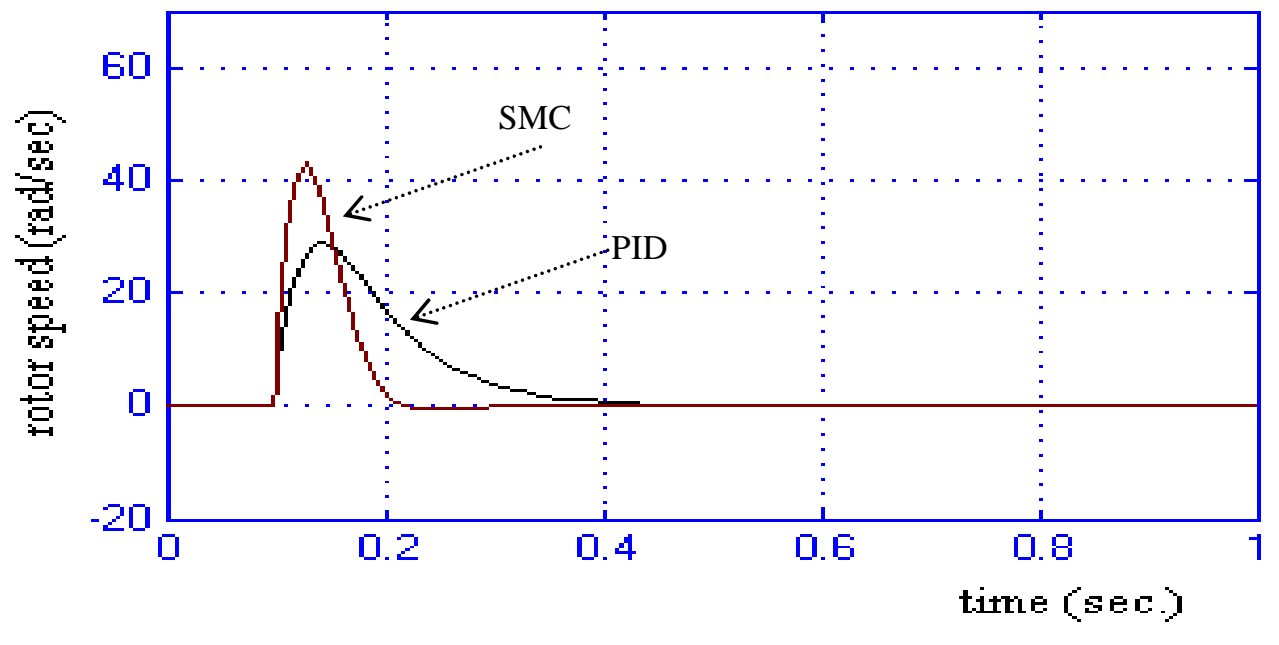

(b)

Fig. 5: Time response of the SMC and optimization tuned PID driven DC servo motor (a- Rotor Position in Rad. , b- Rotor Speed in $\mathrm{Rad} / \mathrm{Sec}$.) 


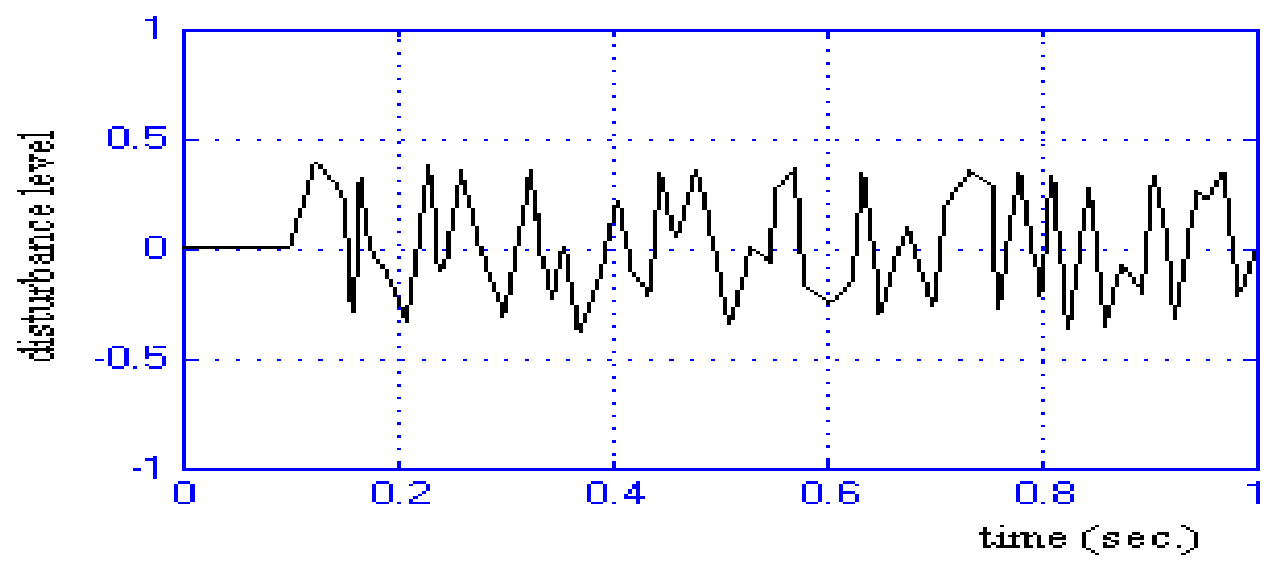

(a)

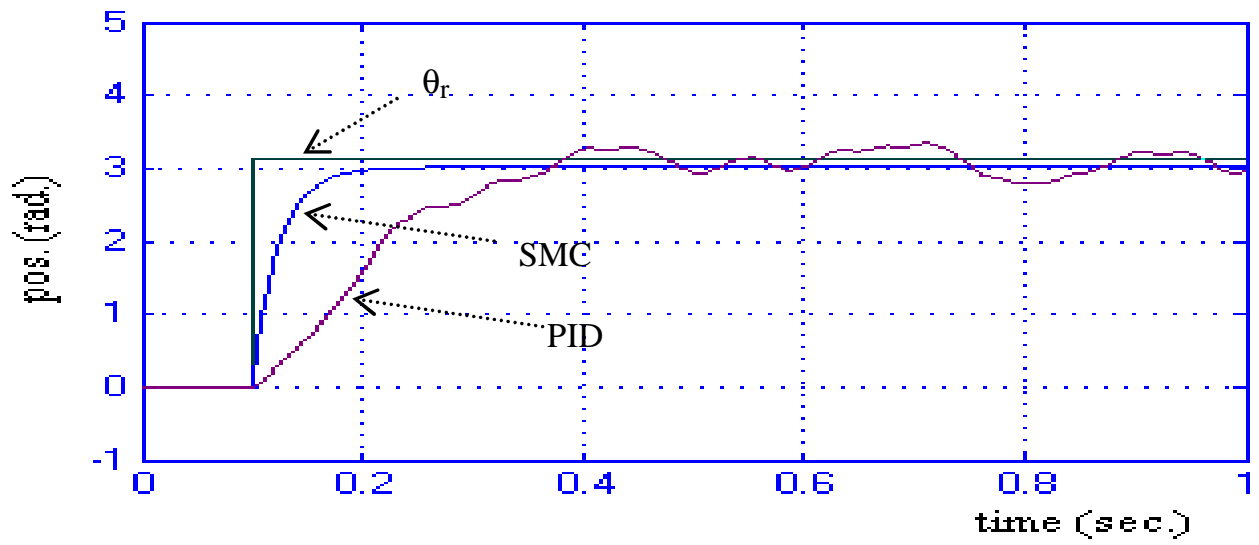

(b)

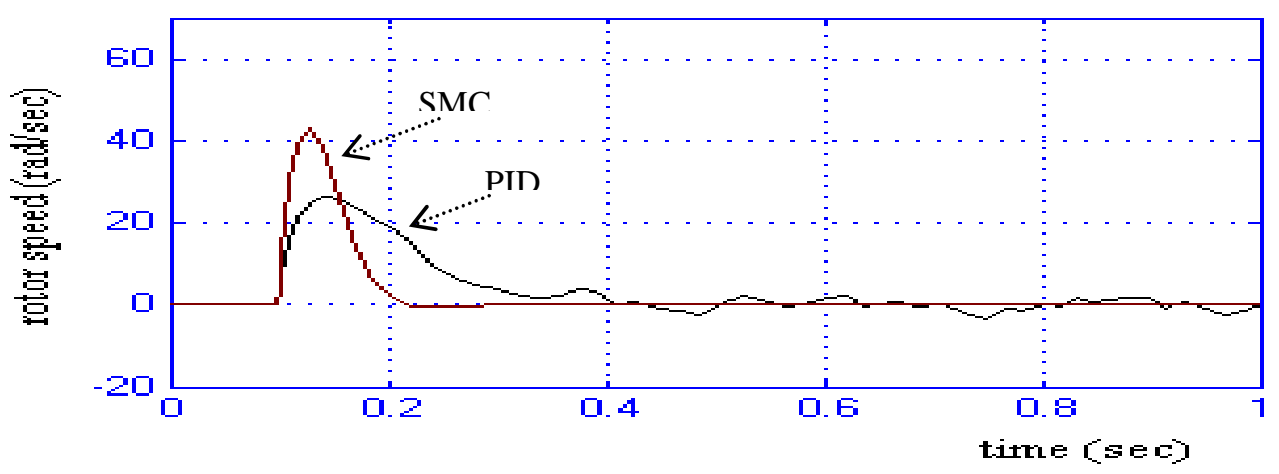

(c)

Fig. 6: Time response of the proposed SMC driven DC servo motor with matched disturbance (a- Disturbance level , b- Rotor Position in Rad. , c- Rotor Speed in $\mathrm{Rad} / \mathrm{Sec}$.) 


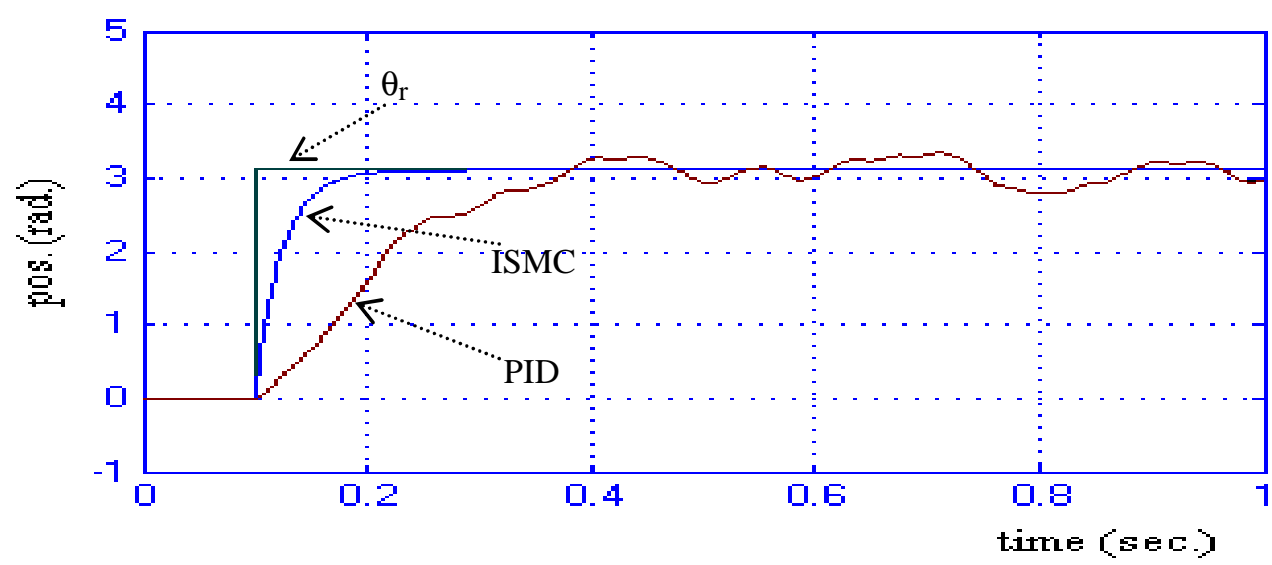

(a)

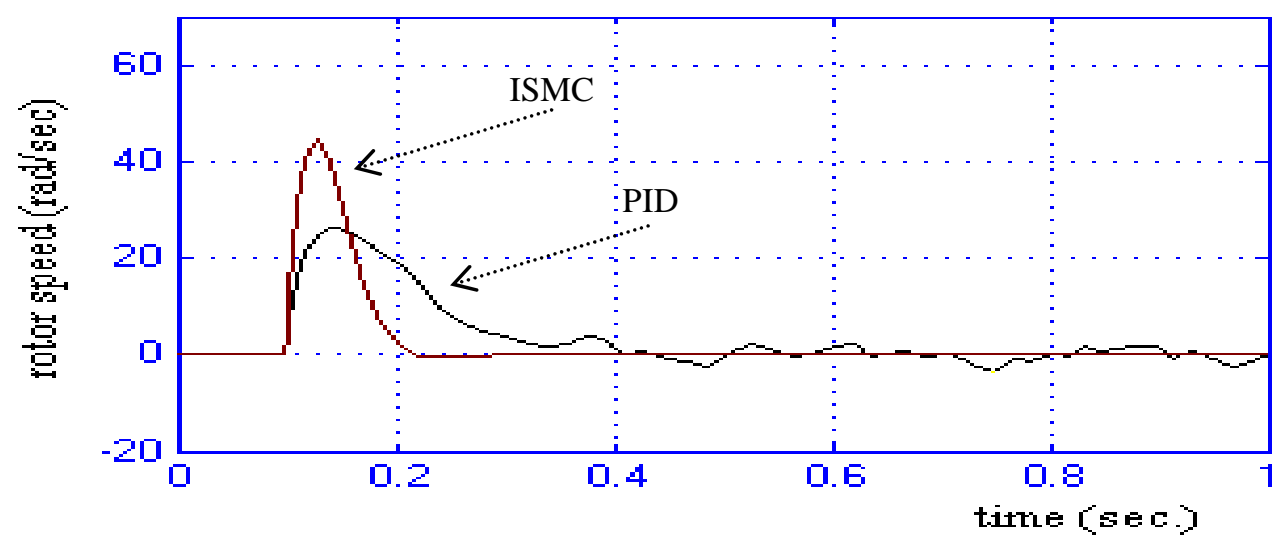

(b)

Fig. 7: Time response of the proposed ISMC and PID driven DC servo motor with matched disturbance(a- Rotor Position in Rad. , b- Rotor Speed in Rad/Sec.)

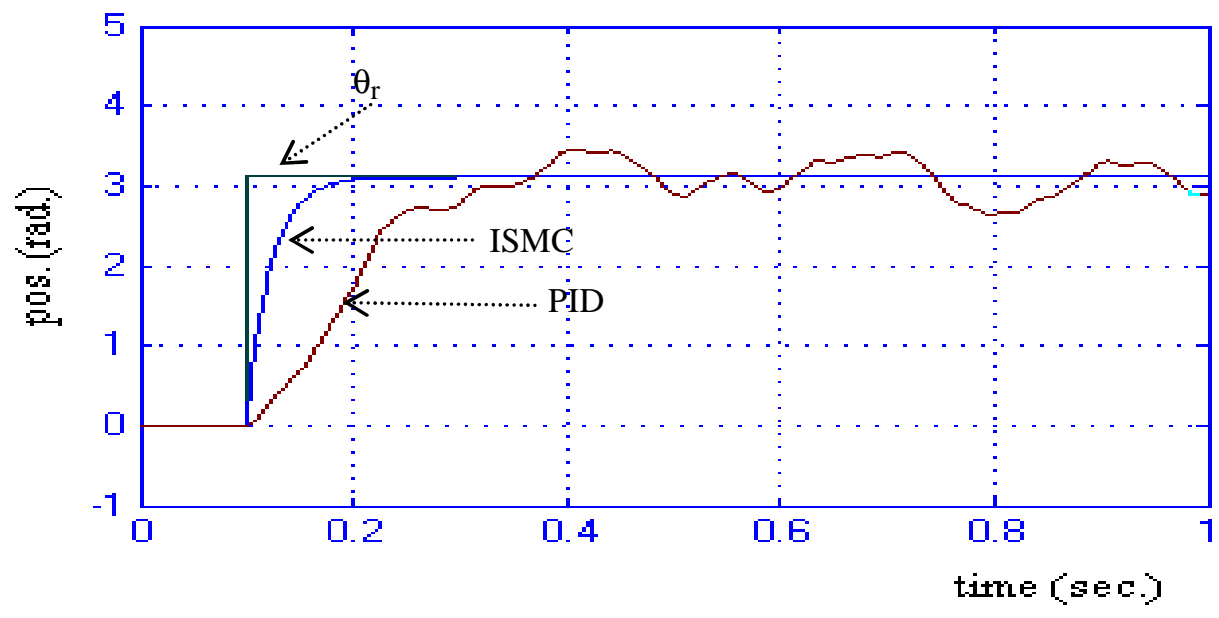

(a) 


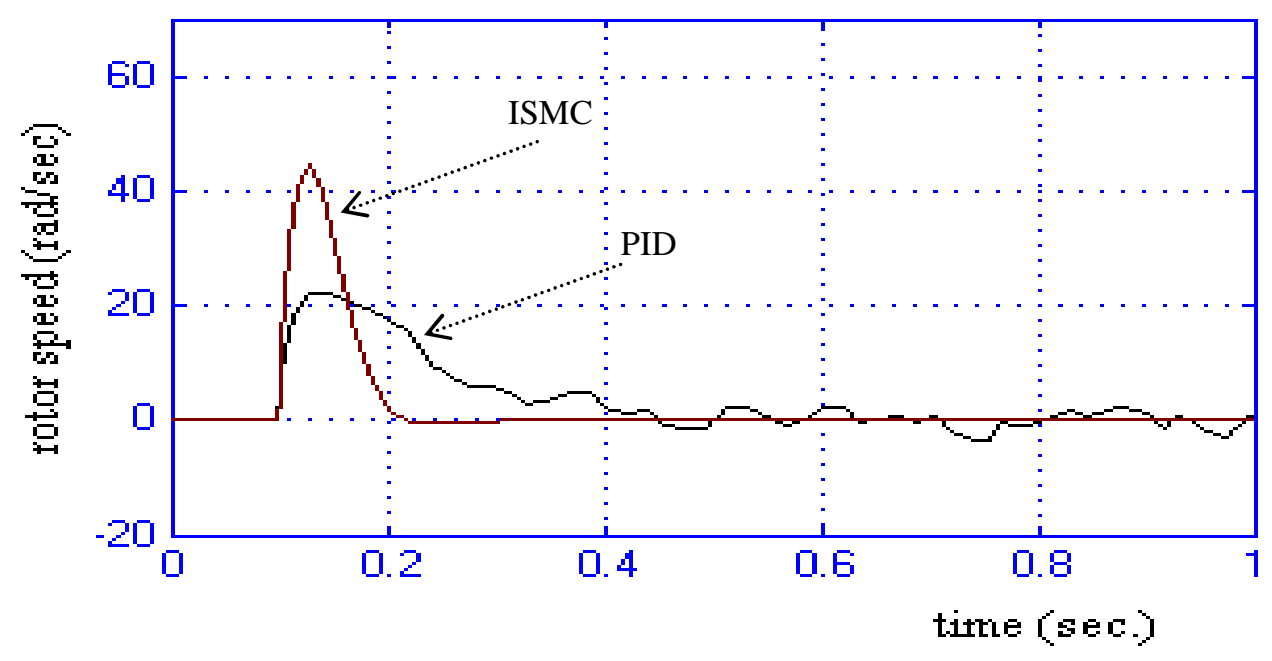

(b)

Fig. 8: Time response of the proposed ISMC and PID driven DC servo motor with matched disturbance and parameters changes (a- Rotor Position in Rad. , b- Rotor Speed in $\mathrm{Rad} / \mathrm{Sec}$.)

Since our concerns are also in robust stability against various model uncertainties, some system parameters have been changed in the following ways:

1. The moment of inertia is decreased by $10 \%$ to be $1.2 \mathrm{e}-5 \mathrm{Kg} \mathrm{m}^{2}$.

2. the armature rotor resistance, is increased by $20 \%$ to be $0.38 \mathrm{ohm}$.

3. The armature rotor inductance is increased by $15 \%$ to be $9.2 \mathrm{e}-5 \mathrm{H}$.

\subsection{Experimental Results}

Configuration of studied system is illustrated in Fig.9. The DC machine parameters used in the experiments are shown in appendix. The hardware of the drive system consists of a four-quadratic MOSFET based chopper. The SMC and the switching controller are implemented related to Figs 3 and 4 . The experimental setup is shown in Fig.10. Moreover, Fig. 11 shows the experimental time response of DC motor position based on SM controller. This figure shows the position response has a chattering and steady state error. To improve the system response, an ISMC is used instead of SMC but the response still has chattering as shown in Fig. 12, which shows the system response has zero steady state error. Fig.13 depicts the system time response with the proposed ISMC with gain changed. This figure shows the system response has zero steady state error and without chattering and also the disturbance doesn't affect the position. While the external disturbance affect the position when PID controller is used as shown in Fig.14. 


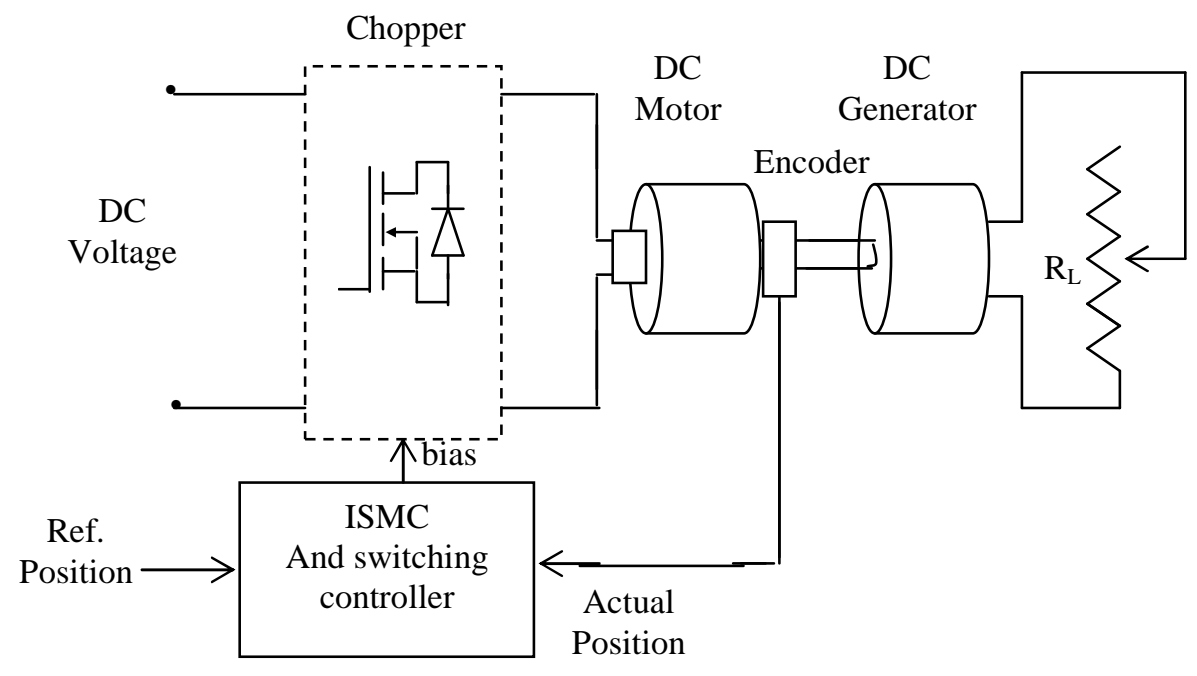

Fig. 9: DC motor drive system configuration

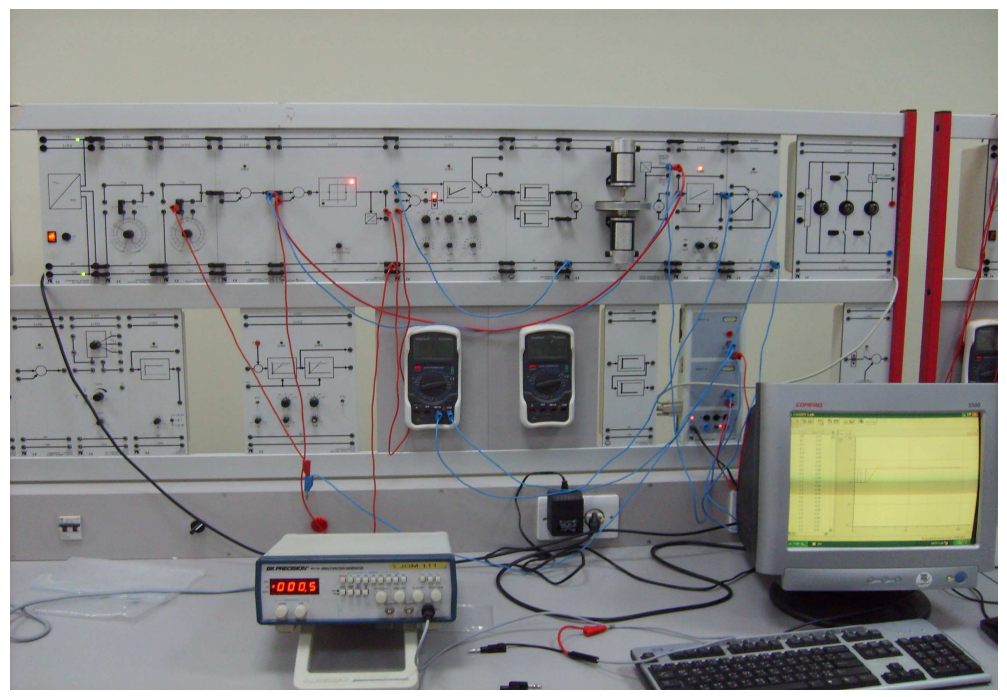

Fig. 10: Experimental setup 


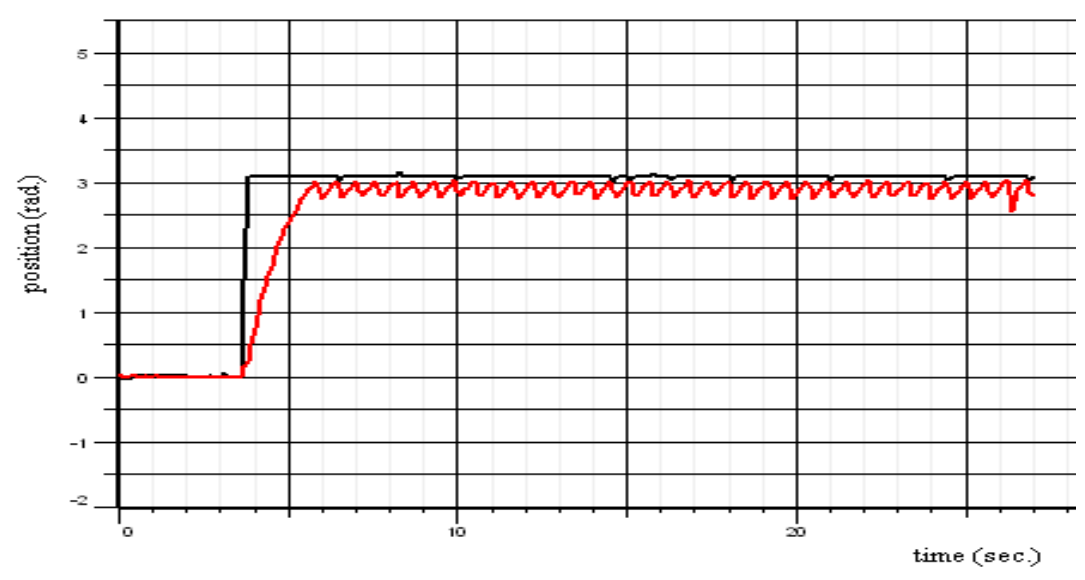

Fig. 11: Experimental time response of the SMC driven DC servo motor

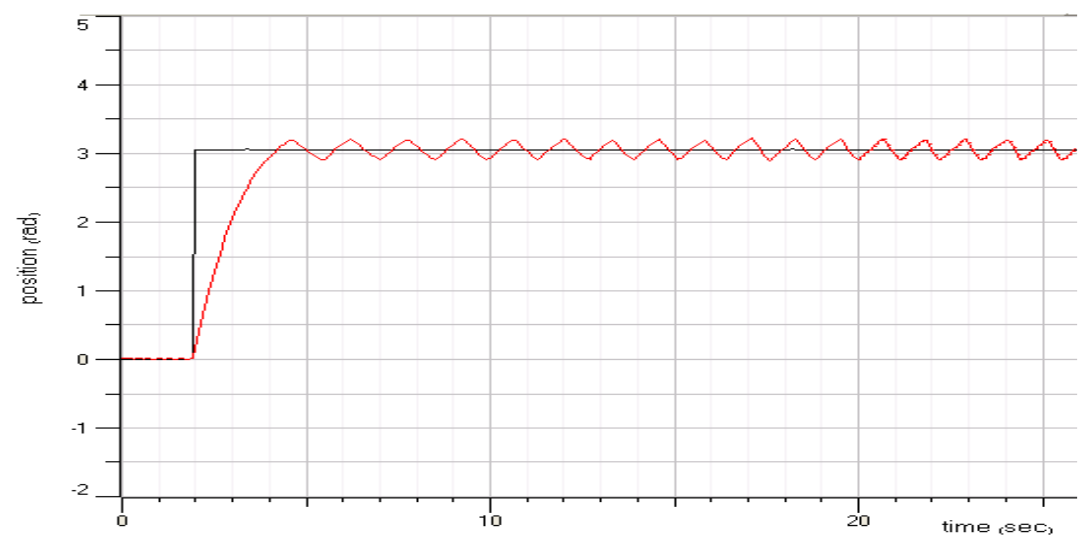

Fig. 12: Experimental time response of the ISMC driven DC servo motor

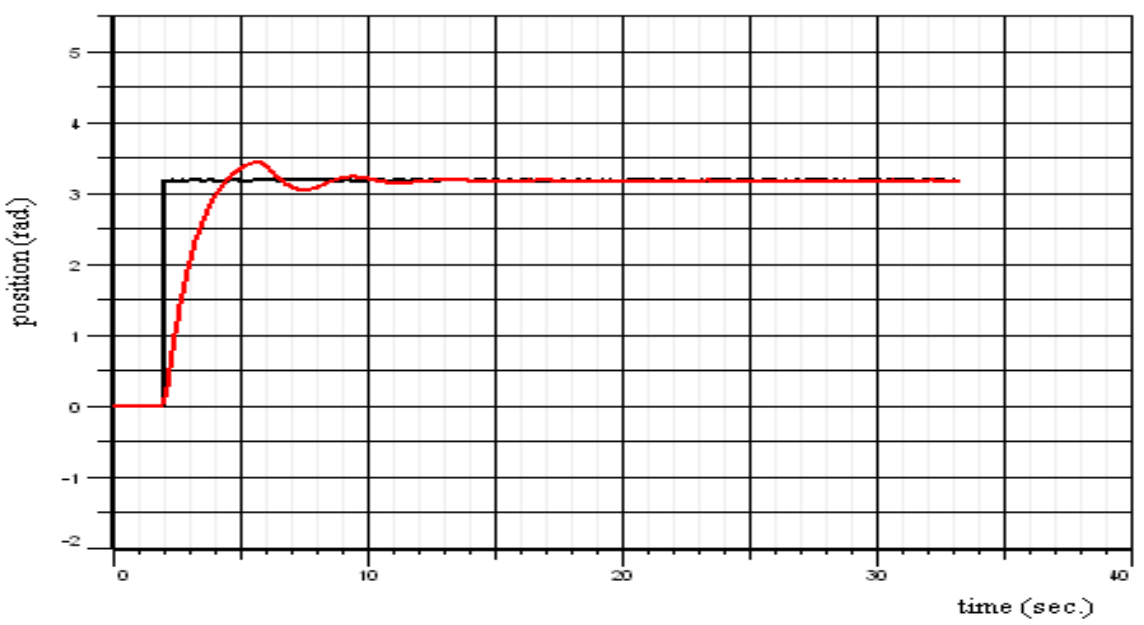

Fig. 13: Experimental time response of the ISMC with gain changed driven DC servo motor 


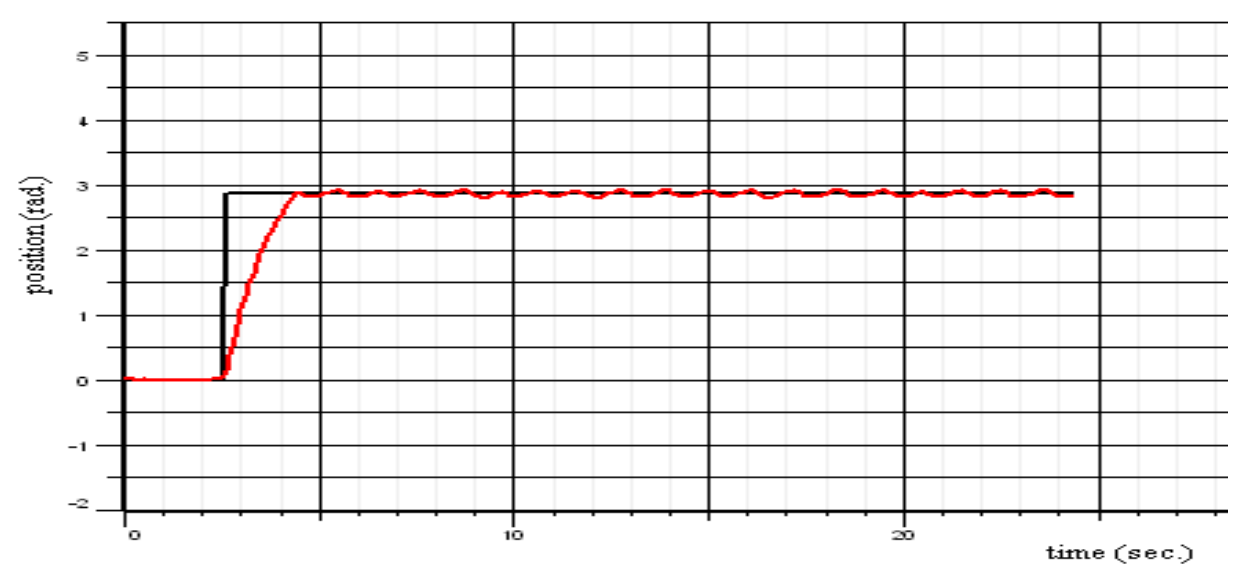

Fig. 14: Experimental time response of the PID controller driven DC servo motor with external disturbance.

Table 1: Settling time and overshoots calculation based on control method techniques.

\begin{tabular}{|c|c|c|c|c|}
\hline Case & Parameters & $\begin{array}{c}\text { PID } \\
\text { control }\end{array}$ & $\begin{array}{c}\text { SM } \\
\text { control }\end{array}$ & $\begin{array}{c}\text { ISM } \\
\text { control }\end{array}$ \\
\hline \multirow{2}{*}{$\begin{array}{c}\text { Position } \\
\text { angle }\end{array}$} & $\begin{array}{l}\text { Settling time } \\
\quad(\mathrm{Sec} .)\end{array}$ & $>1 \mathrm{Sec}$ & $\begin{array}{l}0.3 \mathrm{Sec} . \\
+ \text { S.S.E }\end{array}$ & $0.2 \mathrm{Sec}$ \\
\hline & Overshoots (rad.) & $3 \mathrm{rad}$. & $2.9 \mathrm{rad}$. & $2.9 \mathrm{rad}$. \\
\hline \multirow{2}{*}{ Rotor speed } & $\begin{array}{l}\text { Settling time } \\
\text { (Sec.) }\end{array}$ & $>1$ Sec. & $0.23 \mathrm{Sec}$. & $0.2 \mathrm{Sec}$ \\
\hline & $\begin{array}{l}\text { Overshoots } \\
\text { (rad./Sec.) }\end{array}$ & $\begin{array}{c}25 \\
\mathrm{rad} / \mathrm{Sec} .\end{array}$ & $\begin{array}{c}42 \\
\mathrm{rad} . / \mathrm{Sec} .\end{array}$ & $\begin{array}{c}42 \\
\text { rad./Sec. }\end{array}$ \\
\hline
\end{tabular}

\section{CONCLUSIONS}

In this work, SMC, ISMC with switched gains and PID controllers have been considered for controlling the position of DC motor in servo drive. A comparison method has been included to show the relative advantages and limitations of each method. PID controllers are suitable if there is no disturbance in the system. However, the settling time is longer and contains the chattering when the SMC is applied to the system. Using an ISMC the desired position is obtained. Moreover disturbances don't affect the system in the sliding mode. A novel scheme using Integral sliding mode (ISM) controller with switched gains has been investigated and evaluated in terms of less settling time with no steady state error and also no chattering. Experimental set up verification of the system is implemented to evaluate the effective of proposed SMC, ISMC and conventional PID controller. 


\section{REFERENCES}

[1] Thana Radpukdee " Sliding Mode Control with PID Tuning Technique: An Application to a DC Servo Motor Position Tracking Control", Energy Research Journal 1 (2), pp. 55-61, 2010

[2] Ahmed Kassem and Ali M. Yousef " Servo DC Motor Position Control Based on Sliding Mode Approach", The fifth Saudi Technical Conference and Exhib., (STCEX09), Riyadh, January 11-14, pp.557-561, Saudi Arabia, 2009,

[3] EL Sharkawi M and Huang C., "Variable structure tracking of DC motor for high performance applications". IEEE Trans. on Energy Conversion, V 4, 1989, pp. 643-650.

[4] M.E. Haque, and M.F. Rahman," Influence of stator resistance variation on controlled interior permanent magnet synchronous motor drive performance and its compensation", IEEE Trans. On Energy Conversion, 2001, pp. 2563-2569.

[5] Ciro Attaianese, Vito Nardi, Aldo Perfetto and Giuseppe Tomasso. "Vectorial torque control: A novel approach to torque and flux control of induction motor", IEEE Trans. On Indust. Appl, Vol. 35, No. 6, December 1999, pp. 1399-1405.

[6] Miran Rodic, Larel Jezernic ," Direct torque control of PWM inverter fed ac motors - a survey", IEEE Trans. On Indust. Electronics., Vol. 51, No. 4, August 2004, pp. 744-757.

[7] M. F. Rahman, L. Zhong, M. Haque, and M. A. Rahman, "A direct torque controlled Interior permanent magnet synchronous motor drive without a speed sensor", IEEE Trans. On Energy Conversion, Vol. 18, No.1, March 2003, pp.1722.

[8] Jawad Faiz and S.Hossien Mohseni . " A novel technique for estimation and control of stator flux of a salient pole PMSM in DTC method based on MTPF." IEEE Trans. On Indust. Appl., Vol. 50, No. 2, April 2003, pp. 262-270

[9] M. F. Rahman, E. Haque, and L. Zhong, " Problems associated with the direct torque control of an interior permanent magnet synchronous motor drive and their remedies", IEEE Trans. On Indust. Electronics., Vol. 51, No. 4, August 2004, pp. 799-908.

[10] Luis Romeral, Antoni Aris, Emiliano Aldabs and Marcel. G.Jayne." Novel direct torque control scheme with fuzzy adaptive torque ripple reduction." IEEE Trans. On Indust. Electronics, Vol. 50, No. 3, June 2003, pp. 487-492.

[11] N. R. Idris, and A. M. Yatim, " Direct torque control of induction machines with constant switching frequency and reduced torque ripple", IEEE Trans. On Indust.Electronics., Vol. 51, No. 4, August 2004, pp. 758-767.

[12]A. M. Abdel Ghany and Ahmed Bensenouci, "Improved Free-chattering variablestructure for a DC servomotor position control". $3^{\text {rd }}$ Saudi Technical Conf., V 2, December 2004, pp. 21-30.

[13]Orges Gjini, Takaynki Kaneko and Hirosh Ohsawa. "A new controller for PMSM servo drive based on the sliding mode approach with parameter adaptation". IEE Trans. On IA, V 123, No. 6, 2003, pp. 675-680.

[14]Datta A., Ming-Tzu H. and Bhttacharyy S. P., "Structure and synthesis of PID controllers". Advanced in Industrial Control, Springer-Verlag London Limited, 2000 . 
[15]Astrom K. J. and Hagglund T.., "PID controllers: theory, design and tuning". Instrument Society of America, $2^{\text {nd }}$ edition, 1995.

[16]Yaniv, O. and Nagurka, M., "Robust, PI controller design satisfying sensitivity and uncertainty specifications", IEEE Trans. Automat. Control, V 48, 2003, pp. 20692072 .

[17]Kristiansson, B. and Lennartson, B., "Robust and optimal tuning of PID controllers", IEE Proc. Control theory and application, V 149, 2002, pp. 17-25.

[18] Y. heidari, A. R. Noee, H. Ali Shayanfar,S. Salehi "Robust Control of DC Motor Using Fuzzy Sliding Mode Control with Fractional PID Compensator" , The Journal of Mathematics and Computer Science Vol .1 No.4 ,PP. 238-246, 2010

\section{APPENDIX}

Table 2. Parameter of the DC motor

\begin{tabular}{|l|l|}
\hline Parameters & Values \\
\hline $\mathrm{Ra}$ & $0.316 \mathrm{ohm}$ \\
\hline $\mathrm{La}$ & $0.00008 \mathrm{H}$ \\
\hline $\mathrm{Km}$ & $0.0302 \mathrm{Nm} / \mathrm{A}$ \\
\hline $\mathrm{Kv}$ & $60 / 317 \mathrm{Vs}$ \\
\hline $\mathrm{Va}$ & $24 \mathrm{~V}$ \\
\hline $\mathrm{Jm}$ & $1.34 \mathrm{e}-5 \mathrm{Kgm} 2$ \\
\hline
\end{tabular}

\section{التحقيق العملي للتحمم في وضع محرك تيار مستمر معتمدا على نظريةِ النمطِ المنزلقةٍِ}

\section{التكاملية}

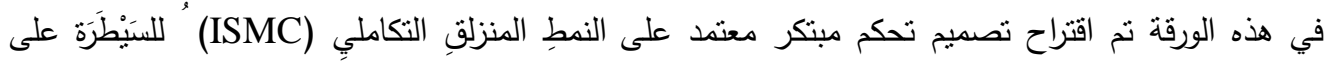
محرك التيار المستمر في وضع المحرك الدافع، العرض والتحليلَ للمحرك التيار المستمر تم توضيحه ، لنتحسين

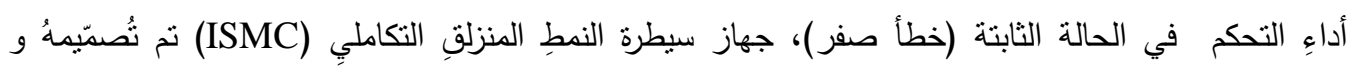

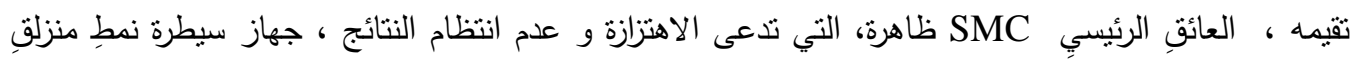

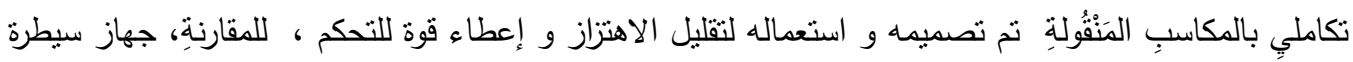

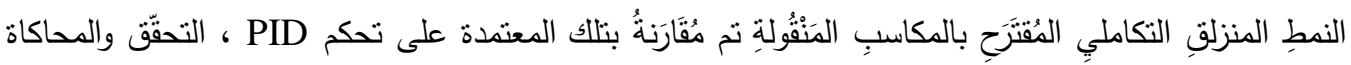

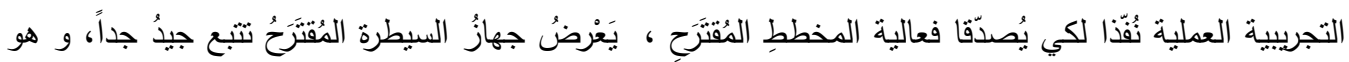

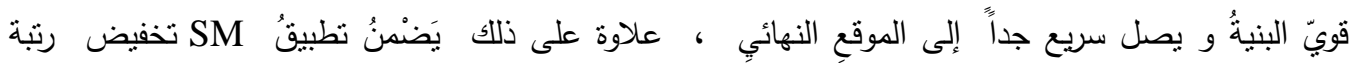

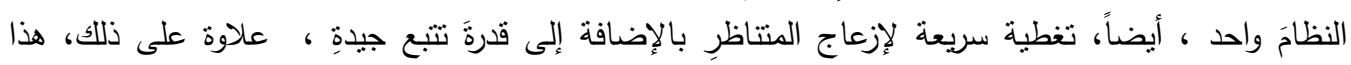

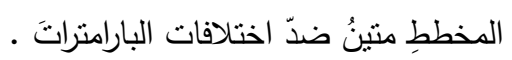

